\title{
Discordant diagnosis of malaria in a family of child refugees from Sierra Leone
}

\author{
Stephanie K Yanow PhD ${ }^{1}$, Daniel Gregson MD $^{2}$, Rupesh Chawla MD ${ }^{3,4}$
}

\begin{abstract}
SK Yanow, D Gregson, R Chawla. Discordant diagnosis of malaria in a family of child refugees from Sierra Leone. Can J Infect Dis Med Microbiol 2013;24(1):e22-e23.

The clinical presentation and diagnosis of malaria involving a family with seven children who arrived in Canada as refugees is reported. Discrepancies in front-line testing using microscopy and rapid diagnostic tests compared with confirmatory testing using real-time polymerase chain reaction in this cluster of symptomatic and asymptomatic patients were identified.
\end{abstract}

Key Words: Diagnosis; Malaria; Refugees

\section{CASE PRESENTATION}

A family of refugees arrived in Calgary, Alberta, on April 12, 2011, from a camp in Sierra Leone. The family included two adults and their two children, along with five nieces and nephews who were orphaned in Sierra Leone. The ages of the four girls and three boys ranged from five to 17 years. All seven children were examined at the Alberta Children's Hospital in Calgary in May 2011. Blood samples collected over three consecutive days were tested for malaria using microscopy and the Binax NOW (Alere, Canada) rapid diagnostic test (RDT). The review of the blood smears and RDTs was performed at Calgary Lab Services within $2 \mathrm{~h}$ of sample collection. Patients were treated, if required, based on the results of the blood smear and RDT. For further confirmation, blood samples were forwarded to the Alberta Provincial Laboratory for Public Health (Edmonton) for testing using real-time polymerase chain reaction (PCR). DNA was extracted from each sample and tested for malaria using pan-plasmodium and multiplex species identification assays (1).

\begin{abstract}
Asymptomatic patients
Four of the children, who were five, six, seven and 17 years of age, were asymptomatic for malaria on medical examination (Table 1). All of these children experienced previous episodes of malaria, which were treated in Sierra Leone, and none had any other significant medical concerns. Two of the patients were found to be negative for parasites according to RDT and blood smear results, which were performed over three consecutive days. The third patient was found to be negative for parasites according to the blood smear results, but was found to be weakly positive according to RDT. For the fourth patient, the blood smears were found to be negative for parasites on days 1 and 3, but Plasmodium falciparum parasites were observed in the blood smear performed on day $2(<0.1 \%$ parasitemia). The same blood sample was also found to be positive for Plasmodium species according to RDT. Both patients who were RDT-positive were treated with a three-day course of atovaquone-proguanil.
\end{abstract}

\section{Symptomatic patients}

Three of the children presented with symptoms consistent with clinical malaria (Table 1). The 10-year-old girl presented with headaches, chills and fever, which were more pronounced at night; she experienced no nausea or vomiting. She experienced an episode of malaria

\author{
Un diagnostic de paludisme problématique dans \\ une famille d'enfants réfugiés de la Sierra Leone
}

Les auteurs exposent la présentation clinique et le diagnostic de paludisme dans une famille de sept enfants arrivée au Canada à titre de réfugiés. Ils ont constaté des variations entre les examens de première ligne à l'aide du microscope et de tests diagnostiques rapides et les tests de confirmation faisant appel à la réaction en chaîne de la polymérase au sein de ce groupe de patients symptomatiques et asymptomatiques.

\begin{tabular}{|c|c|c|c|c|c|c|c|}
\hline \multirow{2}{*}{\multicolumn{2}{|c|}{$\begin{array}{l}\text { Age, } \\
\text { years Symptoms }\end{array}$}} & \multirow{3}{*}{$\frac{\text { Treatment }}{\text { None }}$} & \multirow{3}{*}{$\begin{array}{l}\text { RDT } \\
\text { Neg }\end{array}$} & \multicolumn{3}{|c|}{ Blood smear } & \multirow{3}{*}{$\begin{array}{c}\text { Real-time } \\
\text { PCR }\end{array}$} \\
\hline & & & & \multirow{2}{*}{$\begin{array}{c}\text { Day } 1 \\
\text { Neg }\end{array}$} & \multirow{2}{*}{$\begin{array}{c}\text { Day } 2 \\
\text { Neg }\end{array}$} & \multirow{2}{*}{$\begin{array}{c}\text { Day } 3 \\
\text { Neg }\end{array}$} & \\
\hline 5 & No & & & & & & \\
\hline 6 & No & None & Neg & Neg & Neg & Neg & Neg \\
\hline 7 & No & $\begin{array}{l}\text { Atovaquone- } \\
\text { proguanil }\end{array}$ & $\begin{array}{l}\text { Pos } \\
\text { (weak) }\end{array}$ & Neg & Neg & Neg & Neg \\
\hline 17 & No & $\begin{array}{l}\text { Atovaquone- } \\
\text { proguanil }\end{array}$ & Pos & Neg & $\begin{array}{c}\mathrm{Pf} \\
(<0.1 \%)\end{array}$ & Neg & $\mathrm{Pf} / \mathrm{Po}$ \\
\hline 10 & Yes & $\begin{array}{l}\text { Atovaquone- } \\
\text { proguanil }\end{array}$ & Pos & $\begin{array}{c}\mathrm{Pf} \\
(<0.1 \%)\end{array}$ & $\mathrm{Neg}$ & Neg & $\mathrm{Pf}$ \\
\hline 11 & Yes & $\begin{array}{l}\text { Atovaquone- } \\
\text { proguanil }\end{array}$ & Pos & $\begin{array}{c}\mathrm{Pf} \\
(0.1 \%)\end{array}$ & $\begin{array}{c}\mathrm{Pf} \\
(<0.1 \%)\end{array}$ & $\begin{array}{c}\text { Pf } \\
(0.1 \%)\end{array}$ & $\mathrm{Pf}$ \\
\hline 11 & Yes & None & $\mathrm{Neg}$ & Neg & $\mathrm{Neg}$ & Neg & $\mathrm{Pf}$ \\
\hline
\end{tabular}

in January 2011, which was treated in Sierra Leone. The blood smear from this patient on day 1 was found to be positive for $P$ falciparum according to microscopy, with parasitemia $<0.1 \%$. The blood sample was also found to be positive according to RDT. The patient was treated with a three-day course of atovaquone-proguanil. All follow-up blood smears were found to be negative for parasites.

The 11-year-old girl presented with headache, cough, fever and runny nose that had persisted since her arrival in Canada. She experienced a previous episode of malaria, which was treated in Sierra Leone in January 2011. The first blood smear from this patient was found to be positive for $P$ falciparum (parasitemia of $0.1 \%$ ) and was also found to be positive according to RDT. The patient was admitted to hospital and treated with a three-day course of atovaquone-proguanil. Blood samples reviewed using microscopy on the two subsequent post-treatment days were both found to be positive for parasites $(<0.1 \%$ and $0.1 \%$, respectively).

The 11-year-old boy presented with chills and recent symptoms of headaches and fever that had resolved. The patient experienced many previous episodes of malaria, which were treated in Sierra Leone.

\footnotetext{
${ }^{1}$ Provincial Laboratory for Public Health, Edmonton; ${ }^{2}$ Calgary Lab Services; ${ }^{3}$ Alberta Children's Hospital; ${ }^{4}$ University of Calgary, Calgary, Alberta

Correspondence: Dr Stephanie K Yanow, Provincial Laboratory for Public Health, 8440 112th Street, Edmonton, Alberta T6G $2 J 2$.

Telephone 780-407-7558, fax 780-407-3864, e-mail stephanie.yanow@albertahealthservices.ca
} 
Three consecutive blood smears and RDT performed for malaria were all found to be negative. The patient was not treated.

\section{Confirmatory testing for malaria}

Blood samples from all seven family members were submitted for confirmatory malaria testing using real-time PCR according to the assay described in the study by Shokoples et al (1). A specimen was considered to be positive when the screening and species identification reactions had a cycle threshold value below 40 . Negative samples were tested for inhibition and the integrity of the DNA using an assay for a human gene marker.

Three samples were found to be negative for Plasmodium species according to PCR testing; all of which were in asymptomatic patients (Table 1). The negative PCR results correlated with the negative results according to the blood smear and RDT in two of the three cases. The third sample was also found to be negative for Plasmodium species according to microscopy but was found to be weakly positive according to RDT.

Four samples were positive for Plasmodium species according to realtime PCR testing. One sample confirmed the positive RDT result and the presence of $P$ falciparum parasites according to microscopy. However, a second species of Plasmodium, Plasmodium ovale, was also detected in the sample as a mixed infection. The patient was not symptomatic but was treated with atovaquone-proguanil based on the positive diagnostic tests. PCR results from two samples correlated with positive blood smear and RDT results. Both patients were symptomatic and one was admitted to hospital for treatment of $P$ falciparum infection. The fourth PCRpositive sample was from a child with mild symptoms (chills and resolved fever with headaches). The blood sample was found to be negative according to both the results of the blood smear and RDT but was found to be positive for $P$ falciparum according to PCR.

\section{DISCUSSION}

We describe the diagnosis of four cases of malaria in a family with seven child refugees from Sierra Leone using three diagnostic methods. Both microscopy and RDTs have sensitivities in the range of 20 parasites $/ \mu \mathrm{L}$ to 100 parasites $/ \mu \mathrm{L}$ of blood, while real-time PCR can detect at least 10 -fold lower concentrations of parasites (2). In Alberta, front-line testing for malaria includes microscopy with RDTs, available in some laboratories, followed by confirmatory testing by real-time PCR. This algorithm

\section{REFERENCES}

1. Shokoples SE, Ndao M, Kowalewska-Grochowska K, Yanow SK. Multiplexed real-time PCR assay for discrimination of Plasmodium species with improved sensitivity for mixed infections.

J Clin Microbiol 2009;47:975-80.

2. Rubio JM, Buhigas I, Subirats M, Baquero M, Puente S, Benito A. Limited level of accuracy provided by available rapid diagnosis tests for malaria enhances the need for PCR-based reference laboratories. J Clin Microbiol 2001;39:2736-7.

3. Bell DR, Wilson DW, Martin LB. False-positive results of a Plasmodium falciparum histidine-rich protein 2-detecting malaria rapid diagnostic test due to high sensitivity in a community with fluctuating low parasite density. Am J Trop Med Hyg 2005;73:199-203.

4. Mayxay M, Pukrittayakamee S, Chotivanich K, Looareesuwan S, White NJ. Persistence of Plasmodium falciparum HRP-2 in successfully treated acute falciparum malaria. Trans R Soc Trop Med Hyg 2001;95:179-82.

5. Tjitra E, Suprianto S, Dyer M, Currie BJ, Anstey NM. Field evaluation of the ICT malaria P.f/P.v immunochromatographic test for detection of Plasmodium falciparum and Plasmodium vivax in serves to rapidly identify cases of clinical malaria and to guide therapy, particularly in patients with $P$ falciparum malaria, along with the identification of subpatent infections that can be detected using PCR.

In the cases presented, the three diagnostic methods were concordant in five of the seven patients. In one case, PCR and microscopy were both negative but the RDT result was weakly positive. Given that the patient was asymptomatic for malaria, it suggests that the RDT result may have represented a false positive. The patient reported a previous episode of malaria three months earlier, which was treated in Sierra Leone. The Binax NOW kit is based on detection of the Plasmodium HRPII antigen, which is known to persist in the blood for several weeks after treatment (3-5). It is possible that the RDT was detecting circulating antigen from a previous infection that was treated in Sierra Leone.

We also reported one positive sample that was negative according to both microscopy and RDT. Based on the high cycle threshold value of the real-time PCR result (33.2), this may represent a malaria infection that was associated with very low parasitemia and, therefore, likely below the detection limit of the other methods. It is also possible that the PCR detected residual sexual-stage parasites from a previous infection that persisted in the blood. However, this patient did exhibit mild symptoms that are commonly associated with malaria.

Another interesting case was a mixed infection that was detected using PCR but was not detected using the other methods. The patient sample was positive according to RDT and microscopy for $P$ falciparum, whereas a second infection with $P$ ovale was detected using PCR. The patient was initially treated with atovaquone-proguanil, which kills the blood-stage parasites from both $P$ falciparum and $P$ ovale species. However, infections with $P$ ovale also require treatment with primaquine to kill the liver-stage hypnozoites to prevent relapse infections.

\section{CONCLUSION}

The present cases highlight the challenges of diagnosing malaria in refugee and immigrant populations with some level of acquired immunity, arriving from endemic areas (6-9). Given that refugees may be asymptomatic for malaria, sensitive diagnostic tests based on real-time PCR should be considered. Molecular diagnostic tests can also identify nonfalciparum malaria infections, which are generally more difficult to distinguish using microscopy and are poorly detected using RDTs.

patients with a presumptive clinical diagnosis of malaria in eastern Indonesia. J Clin Microbiol 1999;37:2412-7.

6. Causer LM, Bishop HS, Sharp DJ, et al. Rapid malaria screening and targeted treatment of United States-bound Montagnard refugees from Cambodia in 2002. Am J Trop Med Hyg 2005;72:688-93.

7. Matisz CE, Naidu P, Shokoples SE, et al. Post-arrival screening for malaria in asymptomatic refugees using real-time PCR. Am J Trop Med Hyg 2011;84:161-5.

8. Ndao M, Bandyayera E, Kokoskin E, Gyorkos TW, MacLean JD, Ward BJ. Comparison of blood smear, antigen detection, and nested-PCR methods for screening refugees from regions where malaria is endemic after a malaria outbreak in Quebec, Canada. J Clin Microbiol 2004:42:2694-700.

9. Stauffer WM, Newberry AM, Cartwright CP, et al. Evaluation of malaria screening in newly arrived refugees to the United States by microscopy and rapid antigen capture enzyme assay. Pediatr Infect Dis J 2006;25:948-50. 


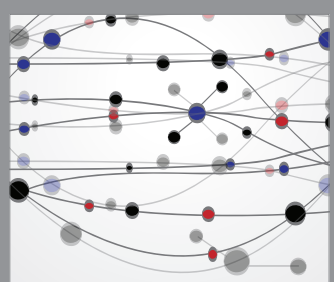

The Scientific World Journal
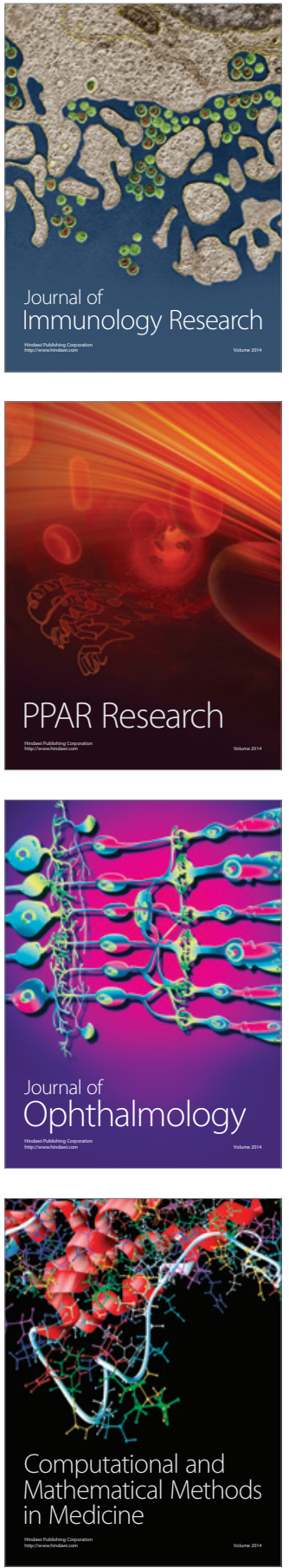

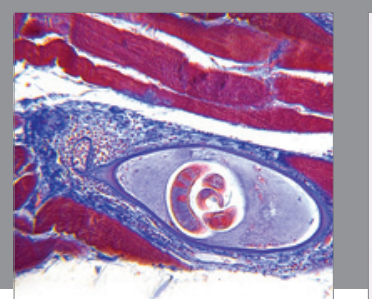

Gastroenterology Research and Practice

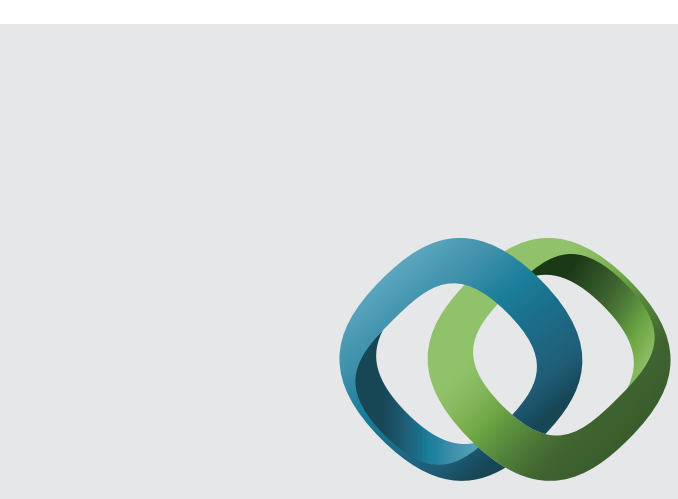

\section{Hindawi}

Submit your manuscripts at

http://www.hindawi.com
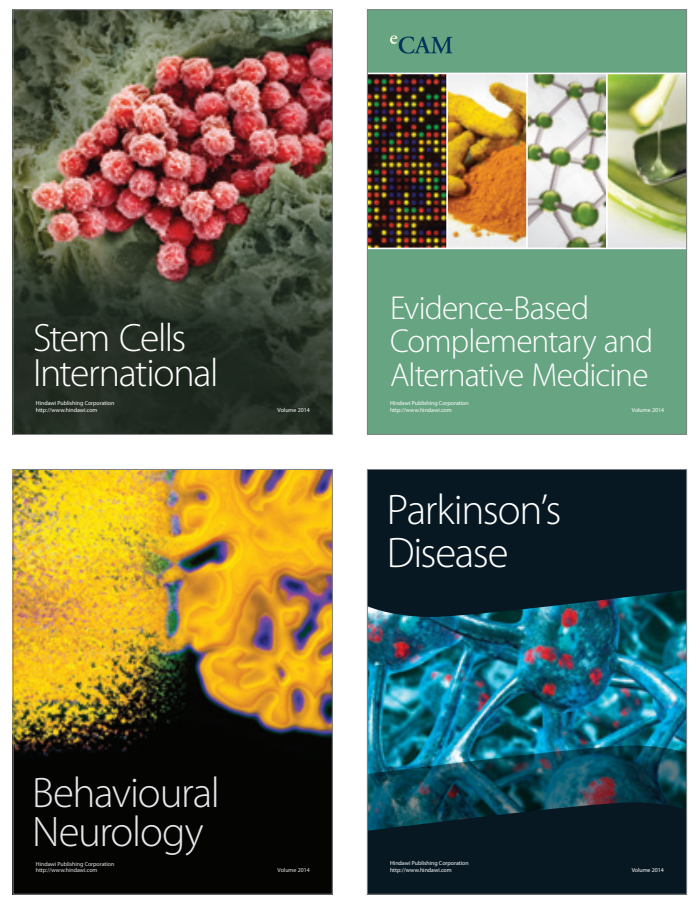
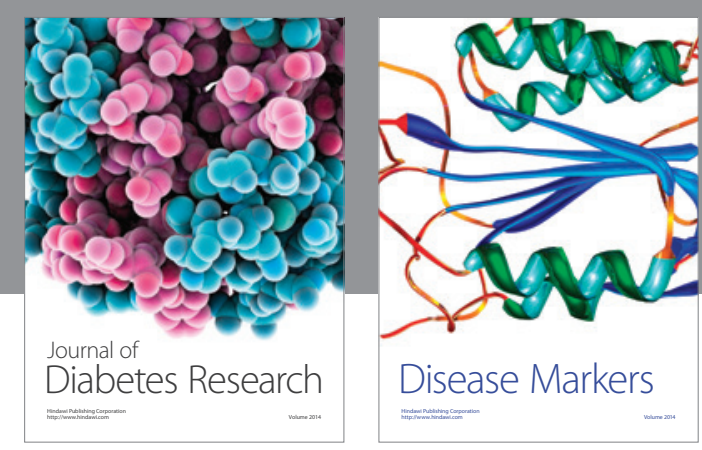

Disease Markers
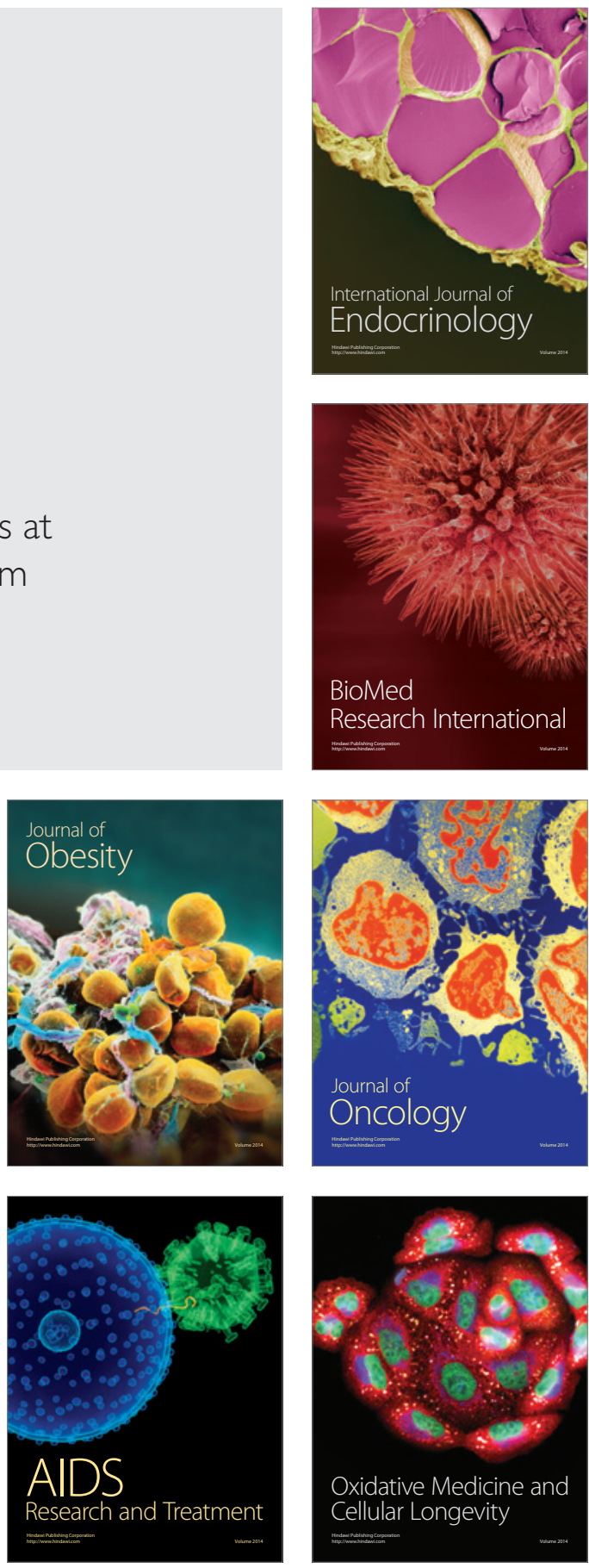